\title{
ANALISIS KELEMBAGAAN GAPOKTAN DALAM KEGIATAN LEMBAGA DISTRIBUSI PANGAN MASYARAKAT (LDPM) DI KABUPATEN GROBOGAN
}

\author{
Arip Wijianto ${ }^{1)}$, Widiyanto ${ }^{1)}$, dan Sapja Anantanyu ${ }^{1)}$ \\ 1)Program Studi Penyuluhan dan Komunikasi Pertanian, Fakultas Pertanian, \\ Universitas Sebelas Maret Surakarta \\ Email: aripkoe@yahoo.com
}

\begin{abstract}
This research aims to explain in detail about the condition of Gapoktan institutional through activities of Reinforcement of Society Food's Distributive Institution (Reinforcement-LDPM) at the Regency of Grobogan considered from superstructur aspect, community profiles of farmers the member of Gapoktan, and organizational profile aspect of the Gapoktan. Qualitative method and descriptive approach were used in this research. The sampling was snowball sampling technique. The technique of data collection used visceral interview, observation, and record-keeping. The tryout of data validity used triangulation source and triangulation method, whereas the data analysis used three main components, i.e. (1) data reduction, (2) data display, and (3) drawing conclusion and verification. Based on the research result, it can be concluded that analysis of Gapoktan institutional considered from superstructure aspects including government policy which influenced Gapoktan institutional. Both the federal government and local government of Grobogan Regency have issued some policies that support the reinforcement activities of Society Food's Distributive Institution (LDPM), but the government policy about Bulog standardization was considered that it was too difficult for Gapoktan institutional. Considered from community profile, the development of Gapoktan institutional has transpired well enough because of having sufficient asset, collective action in both of routine meeting and directive counseling, drawing conclusion by the chief of Gapoktan through discussion and coordination focus, whereas the relationship between Gapoktan institutional with the other Gapoktan has transpired well. Considered from its institutional profile, the Gapoktan still had constraints or problem. Looking to its organization system, the structure of labor units of the reinforcement activities of Society Food's Distributive Institution (LDPM) had not been organized well. The members prefer to profitable jobs than the voluntary Gapoktan. Outsides, the institutional management and resource allocation had not well complied.
\end{abstract}

Keywords: Gapoktan, Institutional, LDPM

\section{PENDAHULUAN}

Gapoktan merupakan lembaga yang strategis yang akan merangkum seluruh aktifitas kelembagaan pertanian (Syahyuti, 2007). Meskipun kelembagaan memiliki peran strategis, namun menurut Soekartawi (2001), aspek kelembagaan, baik kelembagaan formal maupun kelembagaan non formal justru merupakan aspek menonjol yang dapat menghambat jalannya pembangunan pertanian di negara-negara yang sedang berkembang. Hal ini terjadi karena masih banyaknya kelembagaan yang belum optimal yang ada di negara-negara berkembang termasuk di Indonesia. Padahal kelembagaan memegang peranan penting dalam keberhasilan pembangunan pertanian dan pedesaan.

Kelembagaan pertanian Gapoktan dijadikan alat yang penting untuk menjalankan sebuah program. Namun demikian, penggunaan strategi pemantapan kelembagaan banyak mengalami ketidaktepatan dan kekeliruan. Kesalahan selama ini adalah menganggap bahwa permasalahan kelembagaan ada di tingkat petani belaka, bukan pada superstrukturnya, padahal mungkin permasalahan ada pada pelaksananya (Warsana, 2011). Karena banyaknya permasalahan dalam tubuh kelembagaan Gapoktan, maka diperlukan penelitian untuk menganalisis kelembagaan Gapoktan. Peneliti sengaja memilih Kabupaten Grobogan, karena Kabupaten Grobogan adalah Kabupaten penyangga beras di Provinsi Jawa Tengah. Produksi padi kabupaten Grobogan pada tahun 2009 menempati urutan kedua setelah Kabupaten Cilacap. Untuk tahun 2009, Gapoktan di Kabupaten Grobogan yang menerima bantuan Bansos dalam bentuk penguatan LDPM adalah Gapoktan Sidodadi 
Desa Latak, Kecamatan Godong, Gapoktan Amanah Desa Kluwan Kecamatan Penawangan, dan Gapoktan Setiti Desa Curut Kecamatan Penawangan.

Tujuan dari penelitian ini, yaitu: untuk mengkaji lebih dalam mengenai kondisi kelembagaan Gapoktan melalui kegiatan Penguatan Lembaga Distribusi Pangan Masyarakat (Penguatan-LDPM) di Kabupaten Grobogan ditinjau dari segi superstruktur, profil komunitas (community profile) petani anggota Gapoktan, dan dari segi profil kelembagaan (organizational profile) Gapoktan desa tersebut.

Penguatan Gapoktan sangat tergantung pada upaya-upaya pengembangan yang dilakukan anggota kelembagaan tersebut untuk menjadi lembaga yang mampu mengatasi permasalahan yang ada. Kelembagaan merupakan hal yang komplek karena banyak faktor yang mempengaruhi keberlangsungan kelembagaan itu. Kelembagaan tidak bisa hanya dilihat dari segi internal kelembagaan tetapi juga dari segi eksternal kelembagaan yang mempengaruhi kegiatan kelembagaan tersebut. Oleh sebab itu, penganalisisan kelembagaan tersebut sangat diperlukan agar kondisi yang sebenarnya dapat diketahui secara mendalam dan dapat menentukan langkah perbaikan jika masih terdapat kelemahan dalam kelembagaan tersebut guna kemajuan kelembagaan yang dijalankan.

Kompleksnya faktor yang mempengaruhi kondisi kelembagaan menjadikan permasalahan dalam penelitian ini, yaitu: bagaimana kondisi kelembagaan Gapoktan di Kabupaten Grobogan ditinjau dari segi superstruktur, profil komunitas (community profile) petani anggota Gapoktan, dan dari segi profil kelembagaan (organizational profile) Gapoktan.

\section{METODE PENELITIAN}

\section{Desain Penelitian}

Desain penelitian yang digunakan dalam penelitian ini adalah penelitian kualitatif. Menurut Sutopo (2006), penelitian kualitatif melibatkan kegiatan ontologis, data yang dikumpulkan terutama berupa kata-kata, kalimat, atau gambar yang memiliki arti lebih bermakna dan mampu memacu timbulnya pemahaman yang lebih nyata daripada sekedar sajian angka atau frekuensi.

\section{Lokasi Penelitian}

Teknik penentuan wilayah dilakukan secara (purposive) (Faisal, 2001). Lokasi yang dipilih adalah Kabupaten Grobogan karena Kabupaten Grobogan merupakan kabupaten penyangga beras di Provinsi Jawa Tengah.

\section{Metode Cuplikan (Sampling)}

Penentuan sampel dalam penelitian ini dilakukan secara purposive atau disengaja. Sampel dalam penelitian ini adalah subyek dan informan. Subyek terdiri dari Ketua Gapoktan Sidodadi Desa Latak, Kecamatan Godong, Ketua Gapoktan Amanah Desa Kluwan Kecamatan Penawangan, dan Ketua Gapoktan Setiti Desa Curut Kecamatan Penawangan, kemudian Sekretaris Pengelolaan Cadangan Pangan, Ketua distribusi/pemasaran/ pengolahan dan penyuluh pertanian lapang. Informan yang digunakan dalam penelitian ini adalah Kasie Distribusi Pangan Badan Ketahanan Pangan daerah Grobogan, Koordinator BPP Kecamatan Godong dan Penawangan, dan Kepala Desa Latak, Kluwan, dan Curut. Peneliti memilih informan yang dipandang paling tahu, sehingga pilihan informan dapat berkembang sesuai dengan kebutuhan dan kemantapan peneliti dalam memperoleh data (Patton dalam Sutopo, 2002).

\section{Jenis dan Sumber Data}

Menurut Bungin (2003), sumber data penelitian kualitatif beragam bisa berupa manusia, peristiwa dan lokasi serta dokumen atau arsip. Beragam sumber data menuntut cara atau teknik pengumpulan data yang sesuai dengan sumber datanya guna mendapatkan data yang diperlukan. Adapun sumber data penelitian ini adalah subyek, informan, arsip atau dokumen.

\section{Validitas Data}

Data yang telah berhasil dikumpulkan dan dicatat dalam penelitian harus diusahakan kemantapan dan kebenarannya. Untuk membuktikan validitas data menggunakan triangulasi dan review informan. Trianggulasi merupakan teknik yang didasari pola pikir fenomologi yang bersifat multiperspektif yaitu menarik kesimpulan yang mantap tidak hanya menggunakan satu cara pandang.

\section{Teknik Analisis Data}

Analisis data adalah proses mengatur urutan data, mengorganisasikannya dalam suatu pola, kategori dan satuan uraian dasar 
(Afifudin dan Saebani, 2009). Metode analisis data yang dipilih pada penelitian ini adalah analisis kualitatif. Analisis data dalam penelitian berlangsung dengan proses pengumpulan data diantaranya reduksi data, penyajian data dan verifikasi. Ketiga tahapan tersebut berlangsung secara simultan. Data yang telah dikumpulkan kemudian dilakukan reduksi data guna mendapatkan bagian-bagian terpenting dari data. Setelah direduksi kemudian disajikan, dan yang terakhir dilakukan penarikan simpulan (verifikasi) (Bungin, 2003).

\section{HASIL DAN PEMBAHASAN}

\section{Latar Belakang Terbentuknya Gapoktan}

Gapoktan di Kabupaten Grobogan yang menerima bantuan Bansos dalam bentuk penguatan LDPM tahun 2009 adalah Gapoktan Sidodadi Desa Latak, Kecamatan Godong, Gapoktan Amanah Desa Kluwan Kecamatan Penawangan, dan Gapoktan Setiti Desa Curut Kecamatan Penawangan. Kelembagaan Gapoktan di Kabupaten Grobogan awalnya terbentuk secara musyawarah dan mufakat untuk meningkatkan skala ekonomi dan efisiensi usaha. Gapoktan dibentuk atas dasar (1) Kepentingan yang sama di antara para anggotanya; (2) Berada pada kawasan usahatani yang menjadi tanggungjawab bersama di antara para anggotanya; (3) Mempunyai kader pengelola yang berdedikasi untuk menggerakkan para petani; (4) Memiliki kader atau pemimpin yang diterima oleh petani lainnya; (5) Mempunyai kegiatan yang dapat dirasakan manfaatnya oleh sebagian besar anggotanya, dan (6) Adanya dorongan atau motivasi dari tokoh masyarakat setempat. Gapoktan-gapoktan tersebut awalnya terdiri dari tiga sampai lima kelompok tani. Seiring dengan berjalannya waktu, poktan-poktan ini membutuhkan wadah yang lebih besar lagi karena banyaknya permasalahan yang dihadapi oleh kelompok tani, maka terbentuklah Gapoktan di Kabupaten Grobogan.

\section{Pengembangan Gapoktan}

Kegiatan yang selama ini dilaksanakan oleh gapoktan merupakan program-program dari pemerintah, namun ada beberapa program yang merupakan inisiatif gapoktan. Kegiatan yang pernah dilakukan Gapoktan yaitu program PUAP, program LDPM, sekolah lapang, koperasi simpan pinjam, pembangunan gudang cadangan pangan dan lain sebagainya.

\section{Gambaran Umum LDPM}

Tujuan program LDPM adalah untuk menstabilkan harga gabah ditingkat petani saat panen raya, mengadakan penyimpanan cadangan pangan sehingga dapat digunakan oleh masyarakat ketika musim paceklik, mengubah mindset petani yang subsisten menjadi petani yang komersil sehingga dapat meningkatkan pendapatan dan kesejahteraan petani. Program LDPM dilaksanakan dalam jangka waktu empat tahun untuk sampai ke tahap pasca mandiri

\section{Pelaksanaan LDPM}

LDPM merupakan kegiatan hilir atau pasca panen, kegiatan LDPM antara lain pembelian gabah petani, penyimpanan cadangan pangan, pengolahan gabah menjadi beras, serta penjualan baik gabah maupun beras. Masalah yang timbul dalam pelaksanaan LDPM yaitu belum adanya mitra yang mampu menampung hasil panen petani, ketika hasil panen petani jelek gapoktan tidak berani untuk membeli karena beresiko rugi, selain itu juga masalah administrasi karena kualitas SDM yang kurang dalam mengelola program, tekanan dari pengusaha penggilingan padi, serta terbatasnya dana dan curahan waktu anggota yang kurang karena kesibukan masing-masing.

\section{Superstruktur}

Kebijakan yang pemerintah yang mendukung pengembangan Gapoktan diantaranya adalah pemerintah memberikan kekuasaan penuh kepada gapoktan untuk mengalokasikan dana LDPM sesuai RUG Gapoktan, selain itu pemerintah melalui UPTD Pertanian mengirimkan penyuluh untuk mendampingi kegiatan-kegiatan yang dilaksanakan gapoktan. Sedangkan Kebijakan yang menghambat adalah kebijakan dari Bulog yang menetapkan standar kualitas gabah yang tinggi sehingga petani sulit menembus bulog, selain itu kebijaksanaan pembagian air yang kurang mendukung, kasus utk Desa Latak selalu mendapatkan jatah terakhir, sehingga panen selalu yang terakhir, menyebabkan harga jatuh.

\section{Profil Komunitas}

Batasan Komunitas: Yang terlibat dalam kelembagaan gapontan yaitu anggota dan pengurus gapoktan, pemerintah daaerah, tokoh 
masyarakat, penyuluh. Asset yang dimiliki gapoktan antara lain gudang penyimpanan, lantai jemur, terpal, sabit gerigi, RMU, blower, pedal tleser.

Aksi Kolektif: Penyuluhan, selain itu Gapoktan masih mengadakan rapat rutin yang diadakan setiap bulan di rumah pengurus. Saat rapat membahas simpan pinjam anggota, masalah yang sedang dihadapi petani, membahas kegiatan-kegiatan gapoktan yang akan dilaksanakan, dan menyampaikan inforrmasi dari pemerintah jika ada.

Struktur Kekuasaan: Badan Ketahanan Pangan dan Dinas Pertanian Selaku Penentu Kebijakan, BPP daan Pemerintah Desa Selaku Pembina, sedangkan pengambilan Keputusan bersifat demokratis dan disesuaikan dengan keadaaan serta dapat dipertanggungjawabkan. Untuk memperlancar kegiatannya Gapoktan juga menjalin kerjasama dengan pihak-pihak yang terkait LDPM, seperti Bulog, PT. Sang Hyang Sri dan PT. Pertani.

\section{Internal Kelembagaan}

Karakteristik Utama, meliputi Orientasi utama kelembagaan gapoktan yaitu untuk memenuhi kebutuhan hidup anggota dan mensejahterakan petani. Sifat kerja sistem sosial bersifat demokratis karena semua kegiatan dimusyawarahkan dahulu dan sudah menjadi budaya di dalam masyarakat. Sandaran kontrol sosial adalah budaya (cultural) dan penuh perhitungan dalam melakukan kegiatan. Nilai yang dianut dalam pelaksanaan kegiatan yaitu nilai kepatuhan terhadap aturan dan hasil musyawah bersama.

Aspek Organisasi, meliputi Struktur Organisasi dimana jumlah anggota Gapoktan antara 100-300 orang dan Pembagian kerja disesuaikan fungsinya masing-masing. Sedangkan Pola kekuasaan bersifat distributive, ketua menerima aspirasi dari anggota kemudian mempertimbangkan lalu memutuskan hasilnya dengan persetujuan anggota yang lain.

Tujuan Kelembagaan tertulis dalam AD /ART Gapoktan, sedangkan yang tidak tertulis banyak sekali yang intinya untuk peningkatan kesejahteraan anggota. Sistim perekrutan berjalan dengan sendirinya. Anggota masuk secara sukarela tanpa ada pemaksaan. Mereka menganggap bila masuk dalam Gapoktan akan banyak keuntungan yang didapat. Kepemimpinan dipilih secara demokratis melalui musyawarah. Kekuasaan yang biasanya dilakukan oleh ketua Gapoktan adalah memberi sanksi. Sanksi yang diberikan berupa teguran yang dilakukan dengan pendekatan personal dan berada di luar forum.

\section{Aspek Kelembagaan}

Norma yang mendasari kelembagaan Gapoktan adalah norma kesopanan dan kesusilaan. Sistem penghargaan belum diterapkan dalam kelembagaan begitupula sistem pemberian sanksi. Kultur Kelembagaan didasarkan AD ART kelembagaan. Anggota dituntut untuk mematuhinya namun ada aturan tertulis tentang hak dan kewajiban anggota yaitu mendapatkan pinjaman, dan mendapatkan pelayanan sedangkan kewajiban anggota adalah membayar iuran wajib dan iuran pokok tiap bulan. Kepemimpinan bersifat demokratis, pengurus membuat program kerja kemudian disampaikan dalam musyawarah, ada juga Program Kerja dari pemerintah.

\section{KESIMPULAN DAN SARAN}

\section{Kesimpulan}

Berdasarkan hasil penelitian, analisis hasil dan pembahasan dapat diambil beberapa kesimpulan sebagai berikut : Superstruktur dapat dilihat dari kebijakan pemerintah, kebijakan yang mendorong adalah programprogram pemerintah sebelum kegiatan penguatan Lembaga Distribusi Pangan Masyarakat (LDPM), seperti PUAP dan LUEP, sedang kebijakan yang menghambat yaitu tentang penetapan HPP (Harga Pembelian Pemerintah) yang tidak sesuai di lapang dan standarisasi Bulog yang dirasa terlalu memberatkan Gapoktan di Kabupaten Grobogan sehingga kelembagaan tidak dapat menjual berasnya kepada Bulog. Selain itu pembagian air yang dirasakan masih belum adil. Profil komunitas dapat berjalan baik karena dipengaruhi oleh kebijakan pemerintah, seperti batasan komunitas telah mencakup banyak daerah dan Gapoktan telah mempunyai asset yang cukup; aksi kolektif yang dicanangkan pemerintah baik berupa pertemuan rutin maupun yang dilakukan oleh penyuluh pendamping berjalan dengan baik, petani dapat dengan leluasa menyampaikan masalahnya; pengambilan keputusan yang dilakukan oleh ketua Gapoktan dilakukan secara musyawarah dan mementingkan koordinasi dengan anggota lain; sedangkan 
hubungan kelembagaan Gapoktan di Kabupaten Grobogan berjalan dengan baik.

Dilihat dari profil kelembagaan sendiri, masih terdapat kendala atau masalah-masalah. Karena ditinjau dari keorganisasian, struktur yang dimiliki oleh unit-unit usaha kegiatan penguatan Lembaga Distribusi pangan Masyarakat (LDPM) belum terorganisir dengan baik. Hal ini dikarenakan peran ganda yang dimiliki oleh anggota. Anggota lebih mementingkan pekerjaan yang menghasilkan profit daripada menjadi pengurus kelembagaaan Gapoktan. Selain itu manajemen kelembagaan serta pengalokasian sumber daya belum terpenuhi dengan baik. Sedangkan norma-norma yang terdapat dalam kelembagaan Gapoktan dijadikan pengontrol agar tidak keluar dari tujuan kelembagaan.

\section{Saran}

Petani didorong untuk dapat mencapai standart Bulog karena standart tersebut sebenarnya menguntungkan bagi petani namun Pemerintah juga diharapkan bersifat fleksibel dalam penentuan standart penanaman padi antara musim kemarau dan musim hujan sehingga Bulog dapat terus membeli gabah dan beras dari Gapoktan. Pemerintah diharapkan lebih dapat membantu kelembagaan Gapoktan untuk dapat menata sistem internal kelembagaan yang dapat menghambat pengembangan Gapoktan, terutama dalam unit pemasaran karena unit ini memegang peranan vital dalam kegiatan LDPM. Walaupun dari segi profil komunitas cukup baik, namun masih dirasa perlu untuk menambahan asset yang dimiliki demi pengembangan Gapoktan dan memperbanyak aksi kolektif untuk lebih mempererat hubungan kerjasama.

Anggota Gapoktan di Kabupaten Grobogan sebaiknya merekrut anggota baru yang memiliki waktu yang cukup untuk kelmbagaan agar tidak terjadi peran ganda pada anggota kelembagaan dan kegiatan penguatan Lembaga Distribusi Pangan Masyarakat (LDPM) dapat berjalan sesuai dengan tujuan pemerintah dan kelembagaan.

\section{DAFTAR PUSTAKA}

Bungin, Burhan. 2003. Metodologi Penelitian Kualitatif. PT Raja Grafindo Persada. Jakarta.

Faisal, Sanapiah. 2001. Format-Format Penelitian Sosial. PT. Raja Grafindo Persada. Jakarta.

Soekartawi. 1988. Agribisnis Teori dan Aplikasimya. CV. Rajawali. Jakarta

Sutopo. 2002. Metodologi Penelitian Kualitatif. UNS Press. Surakarta.

Syahyuti. 2002. Penelitian kelembagaan dan organisasi pertanian: konsep, metodologi, dan acuan kerja. Bp2tp.litbang.deptan.go.id. Diakses tanggal 17 Juni 2012 pada pukul 17.00 WIB

Warsana, 2011. Pemantapan kelembagaan pada gapoktan. www. Litbang.deptan.go.id. Diakses pada tanggal 16 Juni 2012 pada pukul 15.00 WIB 